\title{
Analysis of the Difference of the Elderly's Identity and Its Influencing Factors
}

\author{
Zhang Ran, a post-graduate student \\ Institute of Political Science and Law, \\ University of Jinan \\ Jinan, Shandong province, China \\ 250022
}

\author{
Li Zonghua*, a professor \\ Institute of Political Science and Law, \\ University of Jinan \\ Jinan, Shandong province, China \\ 250022
}

\begin{abstract}
This paper analyzes the status of Chinese elderly identity by using the survey data of China's elderly social tracking survey (CLASS) 2012.The results show the obvious tendency of younger identity of the elderly than their actual age and the proportion of identity is higher. Physical health, its changes and life events have a significant impact on the identity of elderly in China; social security has no significant influence on the identity of the elderly, and the identity of the elderly without medical assurance tends to be younger than those with medical security.
\end{abstract}

Keywords-Identity; Aging; Healthy aging; Elderly

\section{QUestion Raised}

The 2017 revised World population Outlook report released by the United Nations shows that Japan's population over 60 years old already accounts for 33 percent of its total population, with 29 percent for Italy and 28 percent for Portugal, Bulgaria and Finland respectively. At the meantime, the tendency of the aging population in China is also accelerating, the elderly population now accounts for 16 percent of the total population. However, with the development and popularization of medical technology as well as the increase of life expectancy, it is inappropriate to define the threshold age of the elderly as 60 years old which was set to be the typical age for retirement. Many foreign studies have shown that the elderly tend to be younger in their identity. There is an obvious tendency towards younger identity of the elderly. For example, the majority of the elderly tend to reject the label of "the elderly", and they tend to believe they are younger than they actually are. The study of Western of and Barrett (2005) found that older people who felt younger than they actually were reported higher levels of life satisfaction, more positive emotions and fewer negative emotions[1]. However, there are only a few studies on the identity of the elderly in China. The growth of the elderly population seems to bring considerable pressure on the government, but more elderly people think that they can continue to play a role in social production, and at the same time, there are some elderly people who chose to be involved in re-employment after retirement ${ }^{[2]}$. Therefore, the issue of the identity of the elderly is an important research topic on the Chinese elderly under the new national circumstances. In the increasingly serious aging environment in China, the study of the elderly identity provides theoretical support for the government to further promote the "active aging" work.

\section{LiTERATURE REVIEW}

Identity originated from the Latin word 'idem", originally meant 'being identical' and then gradually evolved into the English word "identity." There are three explanations of the meaning of "identity": one is the cognition of oneself; another is the cognition of things similar to or identical to one's own essential attribute; the other is the cognition of the group to which one belongs ${ }^{[3]}$.Erik H. Erikson first introduced it into social psychology as a technical term for psycho-social analysis .In the 1940's, Eriksson first used the word "ego identity" in his study of adolescent psychoanalysis, and defined it as a "group psychological phenomenon" from the angle of psychoanalysis and function.

In this paper, the identity of the elderly refers to the selfclassification of the elderly to judge whether they are the elderly or not. Existing studies show that the identity of the elderly is not fixed, and there are great differences in the identity of the elderly ${ }^{[4]}$ in the different historical periods and level of economic development. As to the influencing factors of the elderly' s identity, the existing research shows that with the increasing of age, physical condition is aging and the older the elderly is, the more easily he or she tend to self-identify as 'the elderly'; Women tend to self-identify with 'the elderly' more easily than men ${ }^{[5]}$; the younger identity of the elderly is proportional to the higher level of education, the better income, the higher level of social participation, the healthier physical conditions and the higher level of social security ${ }^{[6]}$;Older people who are retired, widowed and bereaved are more likely to classify themselves as elderly people ${ }^{[7]}$. The research on the identity of the elderly in China is still in the preliminary stage, and the analysis is not mature. The current studies in China mainly use the data from2000 and 2010 to analyze the status of the elderly in China, but the results of the study might be inconsistent with international studies.

The research on self-assessment of health by foreign scholars shows that self-assessment of health can comprehensively reflect the subjective and objective aspects of health status, and it is a good predictor of life risk and the degeneration of physical functions. Domestic scholars also found that there is a close correlation between physical health 
conditions and the elderly's self-assessment. ${ }^{[8]}$ Existing studies show that life events can significantly affect the health of social individuals, and the life events experienced by the elderly in old age can easily bring physiological and psychological changes to the elderly, and then lead to a transformation of the identity of the elderly. Retired, widowed, bereaved elderly people are more likely to classify themselves as elderly people [10].

Therefore, this paper will study the influence of health status, life events and social security on the elderly identity, and put forward the research hypothesis.

\section{RESEARCH DESIGN}

\section{A. Data and samples}

This paper uses CLASS (China Social Tracking Survey for the elderly) survey data in 2012. A total of 1126 samples were collected in the survey, and the final number of samples was 1123 after excluding the severely missing samples were excluded.

\section{B. Dependent variable}

The dependent variable of this paper is the elderly's selfidentity in our country. The questionnaire uses the selfevaluation method to examine the elderly's self-identity. The question is "do you think you are old now?"

\section{Independent Variable}

The independent variables in this paper are physical health, health changes, life events and medical assurance. The problem of physical health is 'what do you think of your current state of physical health?'. The question of health change is: 'what is your current state of health compared with last year?'

In terms of life events, the question is "which of the following important life events have you encountered in the past year?"

In terms of old-age security, the question is: "what kind of basic old-age insurance provided by the local government are you currently involved in?"

In terms of health care, the question is: "are you currently taking part in a health care program?"

\section{Control variable}

Control variables include gender, marital status, education level, religious beliefs, and occupations before retirement.

\section{E. Research hypothesis}

Hypothesis 1: The healthier the physical conditions one has, the younger the identity of the elderly tends to be.

Hypothesis 2: If the health conditions tend to improve, the elderly identity tends to be younger.

Hypothesis 3: If one hasn't experienced any adverse life events, the elderly identity tends to be younger.
Hypothesis 4: The higher the level of pension is, the younger the identity of the elderly tends to be.

Hypothesis 5: The higher the level of medical insurance is, the younger the identity of the elderly tends to be.

TABLE I. BASIC STATUS OF THE SAMPLE

\begin{tabular}{|c|c|c|c|c|}
\hline $\begin{array}{c}\text { variable } \\
\text { name }\end{array}$ & variate-value & $\begin{array}{l}\text { Frequency } \\
\text { ( piece ) }\end{array}$ & $\begin{array}{l}\text { Percentage(p } \\
\text { ercent) }\end{array}$ & $\begin{array}{l}\text { Cumulative } \\
\text { percentage } \\
\text { ( percent ) }\end{array}$ \\
\hline \multirow{2}{*}{ Identity } & no $=0$ & 358 & 31.9 & 31.9 \\
\hline & yes $=1$ & 765 & 68.1 & 100 \\
\hline \multirow{2}{*}{ gender } & female $=0$ & 577 & 51.4 & 51.4 \\
\hline & male $=1$ & 546 & 48.6 & 100 \\
\hline \multirow{2}{*}{$\begin{array}{l}\text { marital } \\
\text { status }\end{array}$} & mateless $=0$ & 228 & 20.3 & 20.3 \\
\hline & Spouse $=1$ & 895 & 79.7 & 100 \\
\hline \multirow{3}{*}{$\begin{array}{l}\text { degree of } \\
\text { education }\end{array}$} & $\begin{array}{c}\text { Primary school } \\
\text { and below }=0\end{array}$ & 375 & 33.4 & 33.4 \\
\hline & middle school=1 & 314 & 28 & 28 \\
\hline & $\begin{array}{c}\text { College and } \\
\text { above }=2\end{array}$ & 434 & 38.6 & 100 \\
\hline \multirow{2}{*}{$\begin{array}{c}\text { pro - } \\
\text { occupation } \\
\text { al situation }\end{array}$} & $\begin{array}{c}\text { Non-managerial } \\
\text { staff }=0\end{array}$ & 927 & 82.5 & 82.5 \\
\hline & $\begin{array}{c}\text { adminis trative } \\
\text { staff }=1\end{array}$ & 196 & 17.5 & 100 \\
\hline \multirow{2}{*}{ religion } & no $=0$ & 959 & 85.4 & 85.4 \\
\hline & yes $=1$ & 164 & 14.6 & 100 \\
\hline \multirow{3}{*}{$\begin{array}{c}\text { in good } \\
\text { condition }\end{array}$} & Unhealthy $=0$ & 290 & 25.8 & 25.8 \\
\hline & commonly=1 & 379 & 33.7 & 58.6 \\
\hline & healthy $=2$ & 454 & 40.4 & 100 \\
\hline \multirow{3}{*}{$\begin{array}{l}\text { Health } \\
\text { change }\end{array}$} & Turn bad $=0$ & 432 & 38.5 & 38.5 \\
\hline & common=1 & 575 & 51.2 & 89.7 \\
\hline & Turn good=2 & 116 & 10.3 & 100 \\
\hline \multirow{2}{*}{ life events } & Without $=0$ & 550 & 49 & 49 \\
\hline & have $=1$ & 573 & 51 & 100 \\
\hline \multirow{2}{*}{$\begin{array}{l}\text { pension } \\
\text { security }\end{array}$} & without $=0$ & 184 & 16.4 & 16.4 \\
\hline & have $=1$ & 939 & 83.6 & 100 \\
\hline \multirow{2}{*}{$\begin{array}{l}\text { medical } \\
\text { security }\end{array}$} & Without $=0$ & 41 & 3.7 & 3.7 \\
\hline & have $=1$ & 1082 & 96.3 & 100 \\
\hline
\end{tabular}

IV. ANAlysis of ELDERLy PEOPLE'S IDENTITY UNDER DIFFERENT VARIABLES

\section{A. Status of elderlypeople's identity in China}

It can be seen from TABLE I that the proportion of elderly people over 60 years old in China who classify them as 'the elderly' is obviously higher than that of those who do not identify with the elderly identity, and the proportion of elderly people who do not identify with the elderly identity is 31.9 percent. Although the elderly in our country who do not comply with the elderly identity count for a the lower proportion, there has been a significant change compared to the 2000 data (17.59 percent) of China 's aged scientific research center and the follow - up survey data in 2010 (21.55 percent). This shows that with the development of the society and the economy, the identity of the elderly in China has indeed changed enormously and the proportion of the elderly identity has been declining with an obvious trend of younger identity of the elderly. 
TABLE II.

DISTRIBUTION OF ELDERLY IDENTITY UNDER DIFFERENT VARIABLES

\begin{tabular}{|c|c|c|c|c|}
\hline \multirow{2}{*}{\multicolumn{2}{|c|}{ variable }} & \multicolumn{2}{|c|}{ Elderly identity } & \multirow{3}{*}{$\begin{array}{l}\text { total } \\
25.8 \\
\end{array}$} \\
\hline & & no & yes & \\
\hline \multirow{3}{*}{$\begin{array}{c}\text { Physiological health } \\
x^{2}=79.531 P=0.000\end{array}$} & unhealthy & 9.8 & 33.3 & \\
\hline & common & 35.5 & 32.9 & 33.7 \\
\hline & healthy & 54.7 & 33.7 & 40.4 \\
\hline \multirow{3}{*}{$\begin{array}{c}\text { Health change } \\
x^{2}=54.308 P=0.000\end{array}$} & Turn bad & 22.9 & 45.8 & 38.5 \\
\hline & No change & 65.1 & 44.7 & 51.2 \\
\hline & Turn good & 12.0 & 9.5 & 10.3 \\
\hline \multirow{2}{*}{$\begin{array}{c}\text { life events } \\
x^{2}=25.387 \quad P=0.000\end{array}$} & none & 38.0 & 54.1 & 49.0 \\
\hline & have & 62.0 & 25.9 & 51.0 \\
\hline \multirow{2}{*}{$\begin{array}{c}\text { pension security } \\
x^{2}=1.755 \quad P=0.195\end{array}$} & none & 14.2 & 17.4 & 16.4 \\
\hline & have & 85.9 & 82.6 & 83.6 \\
\hline \multirow{2}{*}{$\begin{array}{l}\text { medical security } \\
x^{2}=2.997 \quad P=0.090\end{array}$} & none & 2.2 & 4.3 & 3.7 \\
\hline & have & 97.8 & 95.7 & 96.3 \\
\hline
\end{tabular}

\section{B. Distribution of elderly people's identity in China}

It can be seen from TABLE II that there is no significant difference between the physically unhealthy elderly (33.3 percent) and the healthy elderly ( $33.7 \%$ percent) who identify themselves as 'the elderly'. However, the number of healthy elderly (54.7\%) who did not identify them as 'the elderly' is much more than the unhealthy elderly (9.8\%). Besides, the proportion of the elderly identity that experienced health changes in the past year was 45.8 percent, which was significantly higher than that of the elderly without health changes, indicating that the effect of health changes on the elderly identity is much more obvious. Moreover, 25.9 percent of the elderly who experienced adverse life events classified them as the elderly, which was significantly lower than those who had not experienced adverse life events. In comparison, health conditions, health changes and life events have a strong correlation with the elderly identity. In summary, no adverse life events, less health changes and better health conditions will lead to a younger identity of the elderly.

\section{LOGISTIC REgRESSION ANALYSIS OF ELDERLY PEOPLE'S IDENTITY IN CHINA}

Since the identity of the elderly in China is influenced by many factors, it is necessary to establish a regression model with major variables to further analyze the identity of the elderly in China. Because the dependent variables in this study are dichotomous nominal variables, the binary Logistic regression model is used in this study.

This paper first establishes a basic model composed of social, economic and demographic factors. In this case,

health status, life events and social security are taken into account in turn, and model one, model two and model three are obtained. Finally, a complete model 4 is obtained by incorporating all the research variables into the basic model. The regression results are shown in TABLE III.

The binary Logistic regression model can be expressed as:

$$
\operatorname{Logit}[\mathrm{P}(y=1)]=\mathrm{a}+\beta_{1} X_{1}+\beta_{2} X_{2}+\cdots+\beta_{\mathrm{k}} X_{\mathrm{k}}
$$

In the program, $\mathrm{P}$ is the ratio of self-identity to the incidence of the elderly. y indicates whether or not Chinese old people identify themselves as 'the elderly' $y=0$ says that old people do not identify themselves as the elderly, $y=1$ means that old people identify themselves as 'the elderly'; $\mathrm{a}$ is a constant; $\mathrm{X}$ is a variable that affects the identity of the elderly; $\mathrm{k}$ is the number of variables, in this paper $\mathrm{k}=9$;

\section{A. Health status impact}

In TABLE III Model 1, the occurrence ratio of the elderly's identity on the general old people is 35.2 percent of the unhealthy ones, and the ratio of the physically healthy old people's elderly identity is 26 percent of those unhealthy ones. Besides, the elderly who had no change in their health status still identified themselves as the elderly accounts for 53.9 percent of the elderly identity whose health condition became worse in the past year, but no significant difference was found when their health condition is improved than the past year.

Model 4 shows that under the control of other variables, the occurrence ratio of the elderly's identity on the general old people is 36 percent of the unhealthy ones, and the ratio of the physically healthy old people's elderly identity is 27.7 percent of those unhealthy ones. The incidence ratio of the elderly identity with no change in health status and with improved health conditions was $54.4 \%$ and $53.8 \%$, respectively, of the elderly whose health became worse in the past year. Thus, hypothesis 1 and hypothesis 2 were comfirm.

\section{B. Impact of life events}

The ratio of the elderly identity who experienced life events in the past year was57.8 percent of those who identified themselves as the elderly and had not experienced the life events, so the life events had a significant impact on the elderly identity. Thus, hypothesis 3 was proven. In model 4, after adding other variables, the occurrence ratio of the elderly identity going through life events is 68.1 percent, and life events still have a significant impact on the elderly identity.

\section{Impact of social security}

In TABLE III, both model 3 and model 4 which take other variables into account show that social security has no significant effect on the identity of the elderly, and hypotheses 4 and 5 were rejected.

TABLE III. LOGISTIC REGRESSION ANALYSIS MODEL FOR THE IDENTITY OF THE AgED PEOPLE IN CHINA

\begin{tabular}{|c|c|c|c|c|c|c|c|c|c|}
\hline \multirow{2}{*}{ variable } & \multirow{2}{*}{ Variable setting } & \multicolumn{2}{|c|}{ Model one } & \multicolumn{2}{|c|}{ Model II } & \multicolumn{2}{|c|}{ Model III } & \multicolumn{2}{|c|}{ Model IV } \\
\hline & & $\mathrm{B}$ & $\operatorname{Exp}(B)$ & $\mathrm{B}$ & $\operatorname{Exp}(B)$ & $\mathrm{B}$ & $\operatorname{Exp}(B)$ & $\mathrm{B}$ & $\operatorname{Exp}(B)$ \\
\hline gender (female) & male & 0.190 & 1.209 & 0.132 & 1.141 & 0.131 & 1.140 & 0.196 & 1.216 \\
\hline Marital status (no spouse) & Spouse & -0.454 & 0.635 & $-0.558 *$ & 0.573 & $-0.589 * *$ & 0.555 & -0.441 & 0.643 \\
\hline
\end{tabular}




\begin{tabular}{|c|c|c|c|c|c|c|c|c|c|}
\hline \multicolumn{10}{|c|}{ Cont. to TABLE III } \\
\hline \multirow{2}{*}{$\begin{array}{l}\text { Education level (Primary } \\
\text { School and below) }\end{array}$} & middle school & -0.083 & 0.920 & -0.035 & 0.966 & -0.300 & 0.971 & -0.106 & 0.899 \\
\hline & College and above & $-0.477 *$ & 0.620 & $-0.514^{* *}$ & 0.598 & $-0.523 * *$ & 0.593 & $-0.478^{*}$ & 0.620 \\
\hline \multirow{2}{*}{$\begin{array}{c}\text { Occupational } \\
\text { status (Freelancer) }\end{array}$} & rank and file & $-0.628 * *$ & 0.534 & $-0.629 * *$ & 0.533 & $-0.684 * *$ & 0.505 & $-0.615^{* *}$ & 0.541 \\
\hline & administrative staff & $-0.820 * *$ & 0.440 & $-0.903 * *$ & 0.394 & $-0.965 * *$ & 0.381 & $-0.814 * *$ & 0.443 \\
\hline \multirow{2}{*}{$\begin{array}{l}\text { Physical health } \\
\text { (unhealthy) }\end{array}$} & common & $-1.045^{* *}$ & 0.352 & & & & & $-1.022^{* *}$ & 0.360 \\
\hline & health & $-1.346 * *$ & 0.260 & & & & & $-1.283 * *$ & 0.277 \\
\hline \multirow{2}{*}{$\begin{array}{l}\text { Health change } \\
\text { (turn bad) }\end{array}$} & No change & $-0.618 * *$ & 0.539 & & & & & $-0.608^{* *}$ & 0.544 \\
\hline & Turn good & -0.577 & 0.561 & & & & & -0.620 & 0.538 \\
\hline Life events (none) & have & & & $-0.549 * *$ & 0.578 & & & $-0.384^{*}$ & 0.681 \\
\hline $\begin{array}{c}\text { pension security } \\
\text { (no) }\end{array}$ & have & & & & & 0.088 & 1.092 & 0.152 & 1.164 \\
\hline $\begin{array}{l}\text { Medical security } \\
\text { (no) }\end{array}$ & have & & & & & -0.439 & 0.645 & -0.344 & 0.709 \\
\hline
\end{tabular}

\section{CONCLUSION AND Discussion}

According to the analysis above, the overall health status has a significant impact on the elderly identity. With the development of social economy in our country, the level of medical treatment and health has been improved significantly, and the effect of treatment on diseases of the elderly has been improved, which has increased the life expectancy of the elderly. Life events have brought extensive influence on identity, affecting old people both physically and psychologically; but this impact should be controllable, the government, community, family can provide assistance from different levels for the elderly.

In addition, the tendency of the elderly identity shows negative correlation with medical security, that is, the elderly without medical insurance tend to believe he or she is still young, whereas those with medical security are less likely to think so. However, it makes no significant difference on the elderly identity between old-age security and medical security, which is inconsistent with the results of Xie Lili's research. Xie Lili and others state that the elderly without security is more likely to be self-identified as the elderly The reason may be that the popularity of old-age security and medical security is so high that the influence on the elderly is too low to make significant differences.

Some people believe that actively promoting the work of "healthy aging" and safeguarding the physical and mental health of the elderly will increase the burden of the national pension. However, better health status of the elderly will not increase the burden on the nation but reduce the medical pressure caused by the diseases. Therefore, we should look squarely at the status of the elderly and provide a favorable public opinion for carrying out the work of "healthy aging". The government, the community, the family and the group organizations of the elderly also need to take responsibility and play a corresponding role in their work, focusing on preventing the impact of life events in old age on the elderly's physical and mental, so as to provide higher quality social security for the elderly.

\section{REFERENCES}

[1] Du Peng, Wu Xiaolan.(An empirical study on the identity of the elderly in China. Population Studies, 2), 67-72.(In Chinese)

[2] Wu Panpan, Shao Jingjin, he Nian, Zhang Li. Characteristics of Age identity and its relationship with Mental Health in the elderly. Psychological and Behavioral Studies.(In Chinese)

[3] Wang Ying. Analysis of the study of identity and identity Construction [J]. Journal of Henan Normal University (philosophy and Social Science Edition). (In Chinese)

[4] BARAK Bern B. Subjective Age correlates a Research Note [J]. The Gerontologists (1986/26):571-577.

[5] JOHN R LOGAN, RUSSELL WARD, GLENNA SPITZE. As Old as You Feel: Age Identity in Middle and Later Life [J]. Social forms, 1992 (12): 451-467.

[6] Gu Lin, Qiao Xiaochun. Analysis on the influencing factors of health self-assessment of the elderly in China. Population Journal; 2006.

[7] Lu Yu. A study on the Old-age support for the aged in the Countryside of the Big City in the process of urbanization-taking Tianjin as an example [D]. Tianjin: Nankai University, 2014: 33(In Chinese)

[8] Yuan Yayun, Health status, Social factors and elderly identity. Population and Society, 2016.(In Chinese) 